\title{
Presentation
}

Continuing without interruption in the task that began in 1995, our journal persists in its mission to contribute to research and discussion regarding social situations and problems, and analysis of mechanisms for social intervention that arise amongst a wide range of society stakeholders in response to them. Today, this is manifested in a context of increasing population diversity and exacerbated social inequality, thus demanding space for examining emerging social intervention strategies and reconsideration of the theoretical approaches that guide these transformation processes.

In this sense, the latest edition of Perspectivas invites its readers to review a wide-ranging selection of works that come as the result of academic and professional efforts in diverse disciplines of the social sciences, from a broad range of latitudes and institutions. These articles showcase the complex changes that society is currently undergoing, and identify the emergence of problems that require the recognition of new subjectivities, within the framework of a society in which power and wealth continue to be concentrated in an unequal manner. These works have been reviewed by a select and rigorous panel of Latin American experts, allowing us to offer a serious and constructive proposition, to stimulate theoretical discussion and recreate interventions by social workers and other professionals.

Before presenting the articles that bring life to this edition, on behalf of our journal's Chief Editorial Board and the USCH School of Social Work, we would like to extend our thanks to Dr. Ana María Álvarez, who served as editor for this issue. We are deeply grateful for her contributions to making Perspectivas the benchmark journal that it has become, and we wish her all possible success in the new institutional tasks to which she has been appointed.

\section{Research Findings}

This section opens with a work by Lilian Sanhueza, Javiera Saldías, Yasna Contreras, and Paola Pizarro: "Social Support for Pa- 
renthood: experiences in children's programs in Chile", presenting the results of a research project conducted in Araucanía Region with men and women from a wide range of contexts. The findings reveal the difficulties that women first and foremost, and how they affect their parenting tasks.

The following paper presents a qualitative research project conducted by Carolina Monsalve Reyes, María Angélica Parada, Natali Ormeño Stuardo, and Verónica Gómez: "Intergenerational Relations: senior teachers with children in the Socio-Educational Program of Penco, Chile". This study examines the valuation of intergenerational relations within the framework of a socio-educational program in Southern Chile.

Next, the work "Beliefs amongst Haitian Parents: The role of schools in social inclusivity for their children". This publication by Carla Fierro Retamal discusses cultural diversity in education establishments, and makes the case for recognition of belief systems held by immigrants, from a perspective of effective social inclusivity.

Continuing with works that derive from research findings, the next article is titled "Street Soccer as an Educational Tool for Social Transformation in Pedro Aguirre Cerda District: the PAC Gol Organization". This work by Juan Ignacio Gutiérrez comes as the result of a qualitative research project that investigates street soccer as a methodology that, from a Freirean perspective, can be used to address stereotypes anchored in formal education and in elements of traditional soccer.

\section{Analysis and discussion on social intervention}

This section opens with a paper by Verónica Gómez and Fania Cid, "Collaborative experience at the Technical Board to Combat Commercial Sexual Exploitation of Children in Bíobio". The authors report on the work performed by a multi-sector body tasked with overseeing the rights of the youngest people with regard to sexual exploitation. The analysis sets out to examine the struc- 
tural causes that create space for this problem to arise, placing emphasis on the transformation of practices conducted by those who play an intervention role.

\section{Analysis of Social Work, transformations and challenges}

This sections first paper, by Karina Aedo, is titled "Professional Social Action through Social Work in the Child Justice System in Chile". The author offers an analysis of professional action in the context of public policy transformations within the sector, set in a neoliberal society, sparking tension surrounding professional actions when such policies are built on a model of society marked by social inequality and injustice.

Next in this section, author Estefanía Vilches presents an article on "HIV and Prevention Policies in Chile. The importance of enunciating intervention based on social work". In this analysis, the author criticizes current public policy in the health sector, particularly in terms of how the situation of persons living with HIV is addressed. She defends the search for power relationships that reduce society, and thus makes the case for a change in the concept of "preventive intervention".

Rounding off this section, author Johanna Camila Ramírez Mellado's article "Fundamentals of Feminist Clinical Social Work: a perspective built on gender, race, and intersectionality" offers an analysis derived from recent guidelines for professional practice in the health sector, with the goal of examining the situation from a feminist perspective to incorporate a number of concepts and practices into clinical social work. 